\title{
DEEP IMPRESSIONS
}

\author{
Picture perfect.
}

\section{BY JOHN GILBEY}

I turned the tinted glass tablet over in my hands, looked at the perfectly ground edges, felt the silk-like quality of the cool surface and finally held it up and looked though it. The effect was astonishing, unreal, unexpected.

"I suppose you're going to tell me that this is some sort of quantum shit?"

The suited executive at my side smiled a pained, corporate smile and looked around nervously - as though he expected the chaos of the kitchen to have suddenly sprouted thrusting microphones and whirring news cameras.

"I'm not going to tell you anything, John — and I advise you not to ask. The terms of this demonstration are clearly laid out in the agreement, and we are paying you after all..."

Oh, yes - they were paying all right, a sudden windfall that had landed on my kitchen table like manna from a clear blue sky. Enough money to let me finish the book, buy in some kit for the next project and maybe even fix the chimney.

I gently placed the tablet back in its foampadded case, it made me nervous just holding it. "Does this stuff at least have a name? I've got to call it something in the report."

He gave me a sheepish look. "We're calling it 'OwlPlex' ... Sorry, marketing seemed to think the military would like it."

Yes, I'm sure the military will like it. A sheet of glass, barely a centimetre thick, with no wires or power supply - yet it acted as the highest resolution, most powerful, colour-perfect image intensifier I'd ever seen. And I've seen a few, in a shadowy technical career that I no longer like to think about, let alone talk about. I still had some questions though - whether he wanted them or not.

"Where does the power come from? It can't do this without any input."

He smiled again and pointed out of the window, across the beach and towards the hills. "Sunshine. It soaks up energy when light falls on it, then releases it slowly as the light fades - augmenting the photons that

DNATURE.COM

Follow Futures:

3 @NatureFutures

f go.nature.com/mtoodm are passing through it at the time. And before you ask, I really can't say any more. Oh, but don't drop it

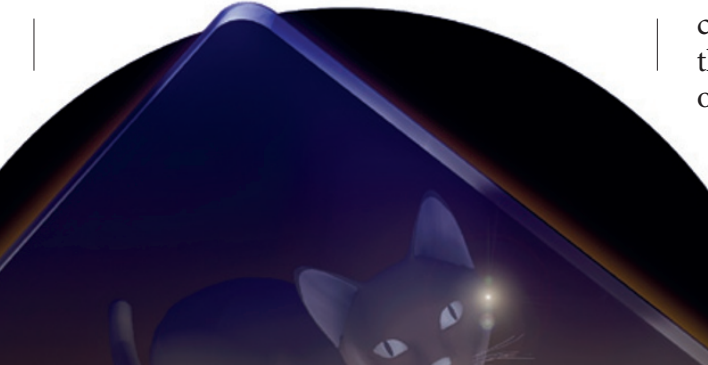

cliffs, the tranquil sweep of the beach where the seals haul out with their pups, the pattern of dry stone walls enclosing bog cotton and coarse grasses.

The old madness returned. It took only an hour to kludge together a holder for the tablet and secure it like a filter to the pin-sharp prime lens of the ancient technical camera. The fridge still held a box of slow, fine-grained monochrome film, so as darkness fell I loaded up the dark-slides, then hefted the tripod onto one shoulder, picked up the camera and set off.

My assumption was that the tablet would allow a constant exposure, but after the first few photos it was clear that the tablet was fading from a lack of daylight.

Cursing, I increased the shutter timing to compensate - guesstimating a 30-second exposure to harvest a final image from the rapidly dimming tablet.

After development, the images were as sharp as I had hoped - with none of the
- it's the only prototype..." He stood up, made some pointed comments about security and edged his way to the door. "I'll be back next week. Remember, we are looking for insights here. Novel applications, things the kids in Development haven't thought of.'

It stayed on the table for four days before I worked up the courage to test it fully. At nightfall I eased the tablet from the case, gripped it carefully in one hand, and turned off the light. One side of the glass glowed like a backlit laptop screen, bright but not too bright, showing me the litter on the floor under the table - including a half chewed mouse that the cat had left there. Making a mental note to clean up, I opened the back door and allowed myself a slow, tuneless whistle as the garden and hillside erupted on the screen into glorious deep autumn hues. The effect was startling, addictive - and I knew exactly what everyone was going to want for Christmas this year.

I awoke in full daylight, with the cat pointedly stropping the end of the sofa in a way that meant he was hungry and wanted feeding now. As he ate, I looked around the room wondering what novel ideas I could come up with to justify my fee. The wall next to the fireplace was home to some of my favourite photographs, shot on $5 \times 4$ film to get the maximum quality. Pictures of the surrounding countryside: the headland with its granite raster artefacts I would have seen from a conventional system. The content of the last image was, like everything to do with the tablet, unexpected. After a few moments of silent thought I wandered out into the kitchen for tea and a long, long ponder strongly regretting that I'd given up drinking.

As I looked out over the long-deserted beach in the dawn light, I tried to visualize it as the tablet had imaged it: wooden fishing skiffs hauled out on the shingle, nets drying on the close cropped turf beyond, a single row of whitewashed cottages with splitstone roofs and racks of drying fish. The scrunch of gravel told me that my executive friend was returning, and I was wryly pleased that I'd found his killer application.

I made a bet with myself that no one had taken a time exposure through the fading glow of dying OwlPlex before. Developers today are too hasty, you see - you need to take a long view, just as OwlPlex itself does in those crucial seconds as some weird internal field collapses. In retrospect though, a less distracted man wouldn't have left the tablet so close to the edge of the table. It was all the opportunity the cat needed.

John Gilbey writes from the academic seclusion of the University of Rural England. Henry Gee, who provided the inspiration for the story, must share the blame. 